\title{
КОМПЕНСАЦИЯ ЗА НЕЗАКОННОЕ ИСПОЛЬЗОВАНИЕ ТОВАРНОГО ЗНАКА
}

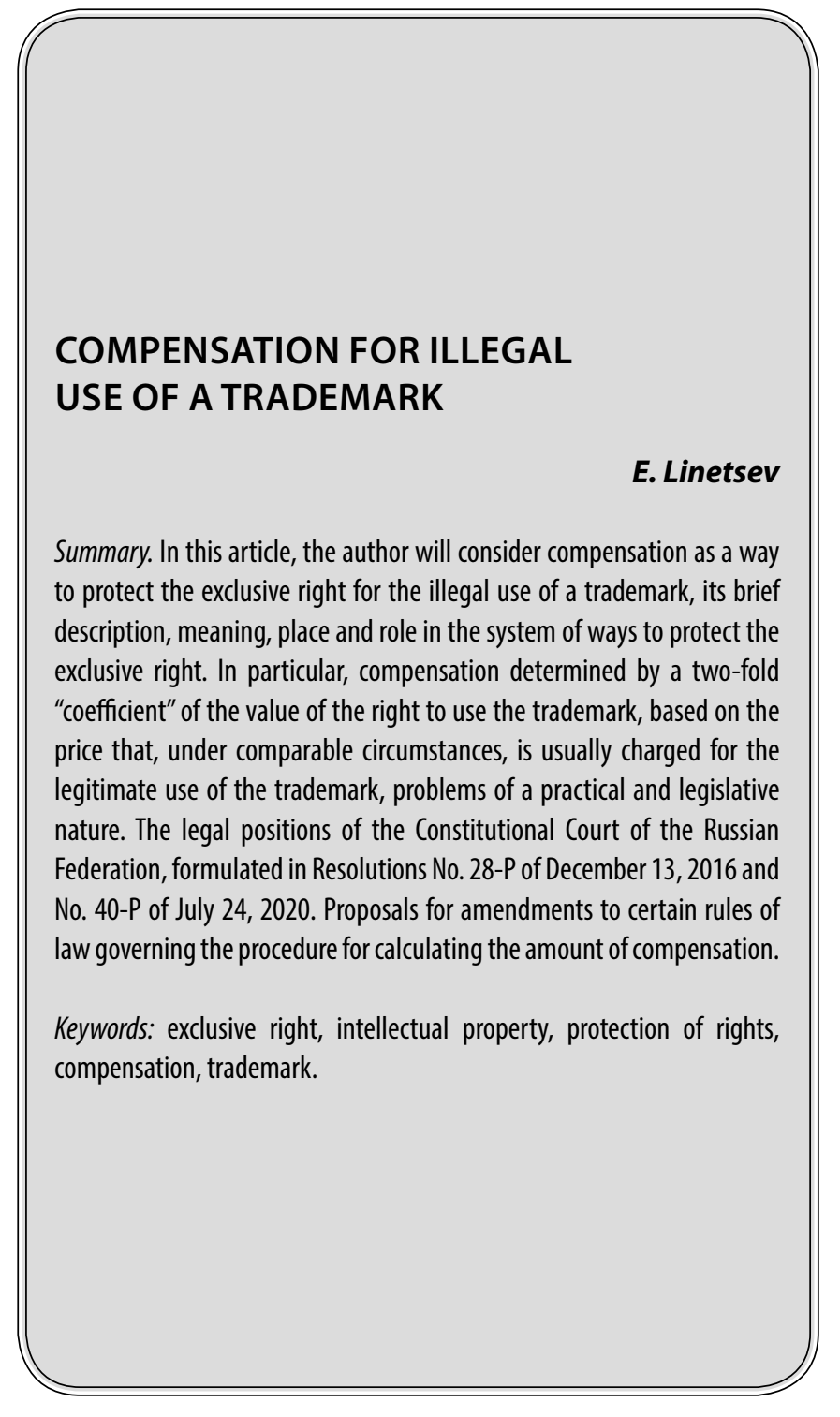

И значально, компенсация как способ восстановления нарушенных прав в интеллектуальной собственности была введена как альтернативная мера применению возмещения убытков, так как порядок их доказывания был достаточно проблематичный для правообладателей. Во-первых, учитывая нематериальный характер интеллектуальной собственности, размер убытков практически невозможно определить.

Во-вторых, для наступления ответственности за причинение вреда необходимо также доказать: противоправность действий нарушителя; причинно-след-
Линейчев Евгений Анатольевич

Аспирант, ФГБОУ ВО «Байкальский государственный университет», г. Иркутск e.lineytsev@mail.ru

Аннотация. В данной статье автор рассмотрит компенсацию как способ защиты исключительного права за незаконное использование товарного знака, ее краткая характеристика, значение, место и роль в системе способов защиты исключительного права. В частности, компенсацию, определяемую двукратным «коэффициентом» стоимости права использования товарного знака, исходя из цены, которая при сравнимых обстоятельствах обычно взимается за правомерное использование товарного знака, проблемы практического и законодательного характера. Правовые позиции Конституционного Суда Российской Федерации, сформулированные в постановлениях от 13 декабря 2016 года № 28-П и от 24 июля 2020 года № 40-П. Предложения по внесению изменений в отдельные нормы права, регулирующие порядок исчисления размера компенсации.

Ключевые слова: исключительное право, интеллектуальная собственность, защита прав, компенсация, товарный знак.

ственную связь между неправомерным действием и причиненным вредом, а также вину нарушителя.

Законодателем, во избежание вынесения законных, но несправедливых решений, была предусмотрена юридическая конструкция, носящая штрафной характер, при которой правообладатель сам мог определять наиболее благоприятный для него способ определения размера компенсации для восстановления нарушенных прав.

На сегодняшний момент компенсация за нарушение исключительных прав на товарный знак среди осталь- 
ных способов защиты является самым эффективным и быстрым для правообладателя [1, с. 39].

Размер компенсации за незаконное использование товарного знака установлен пунктом 4 статьи 1515 Гражданского кодекса Российской Федерации, а именно:

- в размере от десяти тысяч до пяти миллионов рублей, определяемом по усмотрению суда исходя из характера нарушения;

- в двукратном размере стоимости товаров, на которых незаконно размещен товарный знак;

- в двукратном размере стоимости права использования товарного знака, определяемой исходя из цены, которая при сравнимых обстоятельствах обычно взимается за правомерное использование товарного знака.

Сам же размер компенсации, подлежащей взысканию, определяется на усмотрение судьи и на основании установленных критериев: характера нарушения и соблюдения требований разумности и справедливости.

Однако, в последнее время компенсация из способа защиты своих прав превратилась в способ финансового обогащения правообладателя.

По данным исследования по рассмотренным делам за нарушение исключительных прав на товарный знак Арбитражными судами субъектов Российской Федерации в 2018-2020 гг.:

- средний размер компенсации за один товарный знак, заявленный правообладателями, составляет 177000 рублей;

- средний размер удовлетворенных требований за один товарный знак составляет 98000 рублей (порядка 55\% от заявленных сумм) [2, с. 66].

Например, открытое акционерное общество «Рикор Электроникс» обратилось в суд с требованием к Индивидуальному предпринимателю Шемонаевой Г.Н. о взыскании 180000 рублей, составляющих компенсацию за нарушение исключительных права на товарный знак истца. Судом было установлено, что в торговой точке, ответчиком был реализован контрафактный товар-датчик положения дроссельной заслонки, стоимостью 165 руб., на упаковке и корпусе которого имеются изображения, сходные до степени смешения с товарным знаком истца.

Заявителем в данном случае размер компенсации определен в размере двукратной стоимости фиксированного вознаграждения лицензиата по лицензионному соглашению. В обоснование заявленной суммы, истцом представлено лицензионное соглашения, предметом которого является право использовать объект интел- лектуальной собственности на товарах, в том числе на этикетках, упаковках товаров, которые производятся, предлагаются к продаже, продаются, демонстрируются на выставках и ярмарках или иным образом вводятся в гражданский оборот на территории Российской Федерации, либо хранятся или перевозятся с этой целью, либо ввозятся на территорию Российской Федерации; при выполнении работ, оказании услуг; на документации, связанной с введением товаров в гражданский оборот; в предложениях о продаже товаров, о выполнении работ, об оказании услуг, а также в объявлениях, на вывесках и в рекламе; в сети Интернет.

Конституционный суд Российской Федерации постановлениями от 13 декабря 2016 года № 28-П и от 24 июля 2020 года № 40-П указал на возможность снижения суммы компенсации, с учетом фактических обстоятельств дела, ниже минимального предела, установленного гражданским законодательством, при наличии следующих условий.

Во-первых, размер подлежащей выплате компенсации должен превышать размер причиненных правообладателю убытков, в случае наличия возможности их достоверного исчисления.

Во-вторых, обстоятельства дела должны свидетельствовать, что использование товарного знака правообладателя, не является существенной частью предпринимательской деятельности нарушителя.

B-третьих, правонарушение предпринимателем совершено впервые и не носит грубый характер.

Суд, исследовав материалы дела, исходя из цены права использования принадлежащего правообладателю товарного знака, установленной лицензионным договором, заключенным с иным лицом, посчитал возможным снизить размер компенсации до 10000 руб.

По мнению автора, для поддержания баланса законных интересов сторон и соблюдения принципов равенства, разумности и справедливости, правоприменителю необходимо предоставить большую свободу для оценки и исследования обстоятельств конкретного дела, законодатель должен способствовать расширению судейского усмотрения, несмотря на штрафной и пресекательный характер компенсации.

Таким образом, при определении суммы компенсации, исходя из двукратного размера стоимости права использования товарного знака, необходимо проводить параллель между представленным стороной лицензионным договором и действиями нарушителя в каждом конкретном случае. 
Стороны, заключающие лицензионный договор, при определении вознаграждения лицензиара, которое впоследствии участвует в определении размера компенсации, учитывают продолжительность использования товарного знака, в том числе определяют перечень товара и предусматривают введение его в гражданский оборот. При этом, как правило, нарушителем является субъект малого предпринимательства, следовательно, размер компенсации создает риск финансового краха не только как субъекта предпринимательской деятельности, но и как физического лица, так как отвечает всем своим имуществом [3, с. 33].

При этом законодательно статьей 1252 Гражданского Кодекса Российской Федерации предусмотрена возможность снижения размера компенсации в случае «множественности» нарушений, то есть, одним действием нарушены права на несколько объектов интеллектуальных прав, ниже минимального предела, установленного гражданским законодательством, но не более чем на 50 процентов. Данная норма, скорее всего, задумывалась, как исключение, а не как общее правило.
В свою очередь, автор считает, что на данный момент существует большая проблема, которая проявляется в бездействии законодательного органа. В частности, невозможность снижения размера компенсации, определяемого двукратным «коэффициентом» стоимости права использования товарного знака, ниже минимального предела на усмотрение суда, которая может быть решена внесением изменений в статьи 1252, 1515 Гражданского Кодекса Российской Федерации.

В частности, подпункт 2 пункта 4 статьи 1515 Гражданского Кодекса Российской Федерации, автор предлагает изложить в следующей редакции: «в двукратном размере стоимости товаров, на которых незаконно размещен товарный знак, или в двукратном размере стоимости права использования товарного знака способом, примененным нарушителем, определяемой исходя из цены, которая обычно взимается за аналогичное правомерное использование товарного знака». Кроме того, исключить абзац 3 пункта 3 статьи 1252 Гражданского Кодекса Российской Федерации.

\section{ЛИТЕРАТУРА}

1. Лигай В.Ю. Компенсация за нарушение исключительных прав на товарный знак // Юрист. 2020. N5. С. 39-44.

2. Конопленко М.А. Способы расчета размера компенсации за незаконное использование товарного знака // ИС. Промышленная собственность. 2021. 2 C. 62-73.

3. Еремено В.И. // Конституционный суд РФ о компенсации за незаконное использование товарного знака // ИС. Промышленная собственность. 2021. ㄱ3 C. 24-34. 